\title{
Major Parasitic Causes of Organs Condemnation and Direct Economic Loss Attributed to the Condemned Organs in Sheep and Goats brought from Somali, Afar and Borena Areas and Slaughtered at ELFORA Export Abattoir
}

\author{
Sena Zinabu and Debela Abdeta* \\ Wollega university school of veterinary medicine, Ethiopia \\ *Corresponding author: Debela Abdeta, Wollega university school of veterinary medicine, Ethiopia
}

\section{ARTICLE INFO}

Received: 幽 November 19, 2019

Published: 幽 December 02, 2019

Citation: Sena Zinabu, Debela Abdeta. Major Parasitic Causes of Organs Condemnation and Direct Economic Loss Attributed to the Condemned Organs in Sheep and Goats brought from Somali, Afar and Borena Areas and Slaughtered at ELFORA Export Abattoir. Biomed J Sci \& Tech Res 23(3)-2019. BJSTR. MS.ID.003908.

Keywords: Abattoir; ELFORA; Organ condemnation; Parasites; Prevalence; Small ruminant

\section{ABSTRACT}

Each year a large loss from slaughtered animals results due to condemnation of edible organs. Therefore, cross-sectional study was conducted from November 2017 to April 2018 at Bishoftu ELFORA export abattoir to determine the major parasitic cause of organs condemnation in small ruminants brought from Somali, Afar and Borena areas, and to estimate the magnitude of direct economic loss attributed to the condemned organs. 768 small ruminants comprising equal number of sheep and goats were simple randomly selected. Ante-mortem inspection was carried out on arrival in the lairage; temporal identification numbers were given for selected individual animals and abnormalities encountered were recorded. Then after, post-mortem examination was performed in each organ of individual animals along their identification number to detect gross abnormalities and aesthetic reasons that rendered each organ to be rejected from local market.

During this study period out of the total 384 both sheep and goat organs examined, $179(23.3 \%)$ livers, $61(7.9 \%)$ lungs, $4(0.5 \%)$ hearts, $2(0.3 \%)$ kidneys and $20(2.6 \%)$ of both liver and lung were rejected due to parasitic causes: The major causes of condemnation were Stelisia hepatica (11.3\%) and Cysticercus tenuicollis (6.3\%) for liver; lung worm (5.7\%) and Hydated cyst (2.2\%) for lungs; Cysticercus ovis (0.5\%) for heart and Hydated cyst $(0.3 \%$ for kidney and $2.6 \%$ for both liver and lung). Rate of condemnations due to parasitic causes was higher in the liver (23.3\%) than in the lungs (7.9\%) and parasitic causes particularly Stelisia hepatica, Cysticercus tenuicollis and Hydated cyst were the major causes of economic loss through condemnation of affected organs. The overall prevalence of major parasitic cause of organ condemnation in this study was found to be $34.6 \%$ and the total annual economic loss incurred due to this condemnation at the study abattoir was estimated to be 45,379.00 ETB. Therefore, creation of awareness on animal attendants and/or small ruminant owners and abattoir workers about the effect of parasites and safe disposal of condemned organs must be made.

\section{Introduction}

The domestication of animals and plants is considered to be one of the most important developments in history and one of the prerequisites for the rise of human civilizations. These developments triggered the uptake of crop farming and affected the distribution and density of the wild species hunted for food [1]. In Ethiopia, agriculture is the main economic activity and more than $80 \%$ of Ethiopian population is dependent on agriculture of which livestock plays a very important role. According to the report 
of [2], Ethiopia is home to Africa's largest livestock population, and it is the continent's top livestock producer and exporter. From this livestock population, Ethiopia with over 42 million head has the third largest number of sheep and goat among African nations and rank eighth in the world. Small ruminant (sheep and goats) are among economically important livestock in Ethiopia [3].

There are about 25.5 million sheep and 22.78 million goats. They contribute about half of the domestic wool requirements which are about $40 \%$ of fresh skin and $92 \%$ of the value of semiprocessed skin and hide to export trade and a quarter of domestic meat consumption which is estimated that 1,078,000 sheep and $1,128,000$ goats are used in Ethiopia for domestic consumption annually [4]. In Ethiopia, increasing human population, coupled with expanding urbanization and higher average income is putting increasing pressure on the meat supply to meet this demand, millions of food animals are slaughtered every year throughout the country primary for domestic consumption [5]. In this country, for this purpose abattoir plays a major role in providing and serving as sources of information and reference centre for disease prevalence. Meat inspection is conducted in the abattoir for the purpose of screening animal products with abnormal pathological lesions that are unattractive and unsafe for human consumption [6].

Export abattoir including HELMEX, ELFORA, Metahara, Modjo and Luna export abattoirs have been established in Eastern Showa Zone of Oromia Region, Ethiopia to export red meat and edible offal to international market. This enhances the economic development of the country through economical exploitation of the livestock base of the country [7]. The only second to coffee with hides and skins contributing the most, however, currently the overall livestock production constraints in Ethiopia are feed shortages, livestock diseases, low genetic potential of indigenous livestock, and lack of marketing infrastructure and water shortages [8]. Additionally, each year a significant loss results from death of animals, inferior weight gain and condemnation of edible organs and carcass at slaughter during routine meat inspection. This production loss to the livestock industry is estimated at more than 900 million USD annually $[9,10]$ The major causes of organs condemnation during postmortem inspection are disease caused by parasites, bacterial and other abnormalities. The final judgment as to action to be taken with an organ, carcass or part of carcass is based on the total evidence produced by the visual observation, palpation and incision [11]. From these major parasitic diseases such as fasciolosis, hydatidosis, cysticercus and others causes like abscessation and cirrhosis cause a significant economic loss by lowering the productivity of sheep and goats and condemnation of edible organs $[12,13]$. Similarly like many other tropical countries of Africa, it is well known that parasitic diseases are among the major factors responsible for the low productivity of livestock in Ethiopia [14]. These infestations not only cause clinical disease and mortality but also cause economic losses through production losses and condemnation of whole carcass and organs at slaughter. The latter have a huge effect in countries like Ethiopia as export beginner and its effect were seen significant in different abattoirs [15].

Even though several studies have been conducted in different parts of the country at different abattoirs that focused on specific disease conditions like fasciolosis, hydatidosis and Cysticercosis $[16,17]$, there was no work done in ELFORA export abattoir specifically on major parasitic causes of organ condemnation and the associated direct financial impacts in small ruminant brought from Somali, Afar as well as Borena areas. Therefore, this work was conducted to know the major parasitic causes of total organs condemnation and to estimate the direct financial loss because of total organs condemned.

\section{Materials and Methods \\ Description of Study Area}

The study was conducted from November 2017 to April 2018 in ELFORA export abattoir. ELFORA abattoir is found in Bishoftu town, which is located at $900 \mathrm{~N}$ and $400 \mathrm{E} 0$ with an altitude of 1880 m.a.s.l in the central highlands of Ethiopia $47 \mathrm{Kms}$ South East of Addis Ababa. It has annual rainfall of $1151.6 \mathrm{~mm}$ of which $84 \%$ falls down during the long rainy season that extends from June to September and the remaining during the short rainy season that extends from March to May. The mean annual minimum and maximum temperatures is $8.50 \mathrm{C}$ and $300 \mathrm{C}$, respectively, and the mean humidity is $61.3 \%$ [18]. The study animals were small ruminants destined for slaughter. These animals were all males originated from Somali, Afar and Borena areas. They were transported to the abattoir using vehicles.

\section{Study Population and Study Animals}

The estimated sheep and goat population in the areas were about 1,729,159 sheep and 3,461,260 goats in Afar region and $1,022,298$ sheep and 1,519,602 goats in Somali area [4]. The study consisted of 768 small ruminants (384 sheep and 384 goats) brought from Somali, Afar and Borena areas to the abattoir for slaughter. All slaughtered animals were males. The animals were purchased from merchants on weight basis. In this study, small ruminants were categorized into different body conditions (poor, moderate and good) according to the guidelines set by [19]; two age groups, young and adult; and two species, sheep and goats. Sheep and goats with the first pair of permanent incisor teeth were considered as young and those with two and more pair of permanent incisors were regarded as adults [20].

\section{Sampling Procedure and Study Design}

The study was conducted on randomly selected small ruminants slaughtered at the abattoir. For this study simple random sampling method was employed to include the representative sheep and goats those brought from Somali, Afar and Borena and slaughtered from November 2017 to April 2018. Therefore, cross-sectional study design was employed to generate prospective data and 
retrospective data was also collected to calculate/estimate the financial loss.

\section{Sample Size Determination}

The sample size is determined using the formula given by [21].

$$
N=\frac{\left[1.96^{2} * P \exp (1-P \exp )\right]}{d^{2}}
$$

Where,

$\mathrm{N}=$ number of sample size,

Pexp= expected prevalence of organs/carcass condemned and, $\mathrm{d}=$ desired precision level.

Assuming the expected prevalence of organs condemned in respective prevalence to be $50 \%$, since there was no previous survey conducted in this abattoir, the sample size required was 768 (384 sheep and 384 goats) at 95\% confidence interval and at a desired precision level of $5 \%$.

\section{Abattoir Survey}

During ante mortem inspection each of the study animals are given identification with paint on their body and all the necessary independent variables such as age, origin and body condition score was recorded. Body condition score of these animals were also recorded by applying the procedure shown by Nicholson and Butterworth [22]. Ante mortem inspection was conducted on individual animals entering in to the lairage and after they entered the lairage in mass. The general behavior of the animal, gait, posture, cleanliness, clinical signs suggestive of disease and abnormality of any type was registered [23] and judgment was made based on Food and Agricultural Organization recommendation [24]. Sheep and goats with observable abnormality were not allowed for slaughter because they are unfit for human consumption. During postmortem inspection, liver, lung, heart and kidney was thoroughly inspected by visualization, palpation and making systemic incisions to check for the presence of cyst, parasite and/or other abnormalities. Pathological lesions was differentiated and judged according to guidelines on meat inspection for developing countries [25] and classified in to the following categories of judgments: approved as fit for human consumption, conditionally approved as fit for human consumption, totally condemned as unfit for human consumption and partially condemned as fit for human consumption [26].

\section{Assessment of Direct Economic Loss}

All affected organs were rejected from international/domestic market since partial approval was not practiced in the abattoirs and the analysis was based on the annual slaughter capacity of the abattoirs considering market demand, average market prices in international and local market and the rejection rates of specific organs. An average market price of each organ was determined from interviews made with personnel of the abattoir marketing department. The annual slaughter rates were estimated from retrospective abattoir record. The economic loss due to condemnation was estimated by the formula set by [27] as follows.

$$
E L=\sum s r x * C o y * R o z
$$

Where:

$\mathrm{EL}=$ Annual economic loss estimated due to organs and carcass condemnation from international /domestic market.

$\Sigma$ srk=Annual sheep/goats slaughter rate of the abattoir.

Coy=Average cost of each sheep or goat's liver/ lung/ heart and kidney.

Roz=Condemnation rates of sheep/goats/liver/lung/heart and kidney.

\section{Data Management and Analysis}

Data generated was recorded using the format prepared for this purpose and stored in Microsoft excel 2007 program. Analysis was done using Statistical Package for Social Science (SPSS version 20) statistical package. Descriptive statistics was used to determine the proportion of animals whose major visceral organs were condemned, proportion of organs rejected and proportion of infection of helminthes. The association between species of animal, age and body condition score and type of helminth infection were assessed by Pearson chi-square $(\chi 2)$ and difference was regarded statistically significant $p$-value is found to be less than 0.05 at $95 \%$ confidence level.

\section{Results}

\section{Abattoir Survey}

Ant Mortem Examination: The abnormalities found during conducting ante mortem inspection out of the total 768 animals (384 sheep and 384 goats) were 49(12.8\%) sheep's and 47(12.2\%) goats (Table 1). Nasal discharge was highest abnormality detected in sheep's (4.2\%) and (5.2\%) in goats undergone ante mortem examination at Bishoftu ELFORA export abattoir. However, these animals were passed for slaughter with precaution of through postmortem examination as judged by the meat inspectors.

Postmortem Examination: Out of 768 small ruminants examined during the study period, $179(23.3 \%), 61(7.9 \%), 4(0.5 \%)$, $2(0.3 \%)$ and $20(2.6 \%)$ of all livers, lungs, hearts, kidneys and both lung and liver were condemned respectively from gross abnormalities as unfit for human consumption. The most frequently condemned organ was liver followed by the lungs. Significant difference in the rate of organs condemned were not observed with regard to species of animals, age and origin of animals $(\mathrm{P}>0.05)$ but significant difference can be seen with different body conditions $(\mathrm{P}<0.05)$. Percentage of condemnations of Livers 90(23.4\%), Lungs 
$34(8.9 \%)$, Hearts $3(0.8 \%)$, Kidneys $2(0.5 \%)$ and both lung and liver $11(2.9 \%)$ in sheeps likewise $89(23.2 \%), 27(7.0 \%), 1(0.3 \%), 0(0 \%)$ and $9(2.3 \%)$ were condemned in respective organs of goats (Table 2).

The overall liver condemnation due to parasitic causes was 179(23.3\%) (Stelisia hepatica, Cysticercus tenuicollis, Fasciola species and Hydated cysts). There were no statically significant differences between sheep and goats $(\mathrm{P}>0.05)$ and also between liver condemnation rate and age group of both species. This may be due to both of the age groups have similar exposure to ingest the infective stage of the parasite during grazing, but there was significant differences was seen within body condition of both species of animals $(\mathrm{p}<0.05)$. Lung worm followed by hydatidosis were the major causes of lung rejection. There were no statistically significant differences between sheep and goats $(\mathrm{P}>0.05)$ and also with regard to age groups and origin of the animals, but statistically highly significant difference was observed $(\mathrm{P}<0.05)$ with regard to body condition score of the animas.

The 4 total hearts condemned were due to Cysticercus ovis. There were no significant differences observed with regard to the age groups, species, body condition score and also within origin of both species' animals $(\mathrm{P}>0.05)$.

The 2 total kidneys condemned were due to parasite cause, hydatidosis. There were no significant differences observed with regard to the age groups, species, body condition score and also within origin of both species' animals $(\mathrm{P}>0.05)$. The 20 totals both liver and lung condemned were due to parasite cause, hydatidosis. There were no significant differences observed with regard to the age groups, species and also with regard to origin of both species of animals $(\mathrm{P}>0.05)$. A significant difference was observed within body condition score of the animals $(\mathrm{P}<0.05)$.

\section{Assessment of Direct Economic Loss}

The average annual sheep and goat slaughtered rate were estimated to be 20,000 and 60,000 heads respectively, while by taking the average market price of each liver, lung, kidney and heart as 2 ETB, 0.50 cents, 0.60 cents and 0.60 cents respectively, the economic loss due to organ condemnations at a single abattoir at Bishoftu ELFORA export abattoir was estimated. Hence the direct annual economic loss due to rejection of organ was calculated based on average price per organ at ELFORA export abattoir to the formula:

$$
E L=\sum s r x * C o y * R o z
$$

Where:

$E L=$ Annual economic loss estimated due to organs and carcass condemnation from international /domestic market.

$\Sigma$ srk=Annual sheep/ goats slaughter rate of the abattoir.

Coy=Average cost of each sheep or goat's liver/ lung/ heart and kidney.
Roz=Condemnation rates of sheep/goats/liver/lung/heart and kidney.

For liver:

$$
E L=\sum s r x * C o y * R o z
$$

Sheep: $\mathrm{EL}=20,000 \times 2 \mathrm{ETB} \times 0.234=9375 \mathrm{ETB}$

Goat: $\mathrm{EL}=60,000 \times 2 \mathrm{ETB} \times 0.232=27812.5 \mathrm{ETB}$

For lung:

$$
E L=\sum s r x * \operatorname{Coy} * \operatorname{Roz}
$$

Sheep: $\mathrm{EL}=20,000 \times 0.50$ cents $\times 0.089=885 \mathrm{ETB}$

Goat: $\mathrm{EL}=60,000 \times 0.50$ cents $\times 0.070=2109 \mathrm{ETB}$

For heart:

$$
E L=\sum \operatorname{sr} x * \operatorname{Coy} * \operatorname{Roz}
$$

Sheep: $\mathrm{EL}=20,000 \times 0.60$ cents $\times 0.008=93.75 \mathrm{ETB}$

Goat: $\mathrm{EL}=60,000 \times 0.60$ cents $\times 0.0026=93.75 \mathrm{ETB}$

For kidney:

$$
E L=\sum s r x * \operatorname{Coy} * \operatorname{Roz}
$$

Sheep: $\mathrm{EL}=20,000 \times 0.60$ cents $\times 0.005=62.5 \mathrm{ETB}$

For both liver and lung:

$$
E L=\sum s r x * \operatorname{Coy} * \operatorname{Roz}
$$

Sheep: $\mathrm{EL}=20,000 \times 2.5 \mathrm{ETB} \times 0.0286=1432 \mathrm{ETB}$

Goat: EL= 60,000 $\times 2.5 \mathrm{ETB} \times 0.0234=3515.6 \mathrm{ETB}$

\section{Total ground cost of all organs $=45,379.00 \mathrm{ETB}$}

Finally, based on the relevant information mentioned above, the cost associated with condemnation of organs was estimated to be 45,379.00 Ethiopian birr per annum.

\section{Discussion}

The livestock health problem influences on productivity and fertility of herds and the parasitic and other diseases are considered the major one causing a significant loss in the agricultural sector [28]. Meat inspection is conducted in the abattoir for the purpose of screening animal products with abnormal pathological lesions that are unattractive and unsafe for human consumption [6]. Export abattoir including HELMEX, ELFORA, Metahara, Modjo and Luna export abattoirs have been established in Eastern Showa Zone of Oromia Region, Ethiopia to export red meat and edible offals to international market. This enhances the economic development of the country through economical exploitation of the livestock base of the country [15]. An abattoir as a building for butchering can be a source of valuable information of the incidence of animal disease and condition. Some of which may be zoonotic. It is food factory whose primary animals to produce health, wholesome and clean 
products which are safe for human consumption. Inadequate care of those food animals reduce their productivities and expose them to different forms of disease agent which may became hazardous to man and his environment [29]. The current study which was carried out in Bishoftu ELFORA export abattoir revealed that different abnormalities like Nasal discharge (4.7\%), depression (3.6\%), coughing $(2.5 \%)$ and Localized swelling (1.7\%) were detected in $96(12.5 \%)$ heads of sheep's and goats (Table 1). However, these animals were passed for slaughter with great caution thorough postmortem examination because some of these different abnormalities either might be symptom of diseases or resulted from the poor transportation to the abattoir. The present study revealed that out of the total 768 slaughtered small ruminants 179 (23.3\%) , 61 (7.9\%), 4(0.5\%), 2(0.3\%) and 20(2.6\%) of livers, lungs, hearts, kidneys and both livers and lungs respectively were rejected from market due to their gross abnormalities (Tables 2a \& 2b).

Table 1: Abnormalities Encountered During Ante Mortem Examination.

\begin{tabular}{|lccccccc|}
\hline \multicolumn{7}{c}{ Sheep } & \multicolumn{3}{c|}{ Goat } \\
\hline Condition or & Young & Adult & Total & Young & Adult & Total & \\
Abnormality & & & & & & \\
\hline Nasal discharge & $6(4.7 \%)$ & $10(3.9 \%)$ & $16(4.2 \%)$ & $6(4.3 \%)$ & $14(5.7 \%)$ & $20(5.2 \%)$ & $\begin{array}{c}\text { Passed for } \\
\text { attentions during PMI }\end{array}$ \\
Depression & $7(5.5 \%)$ & $8(3.1 \%)$ & $15(3.9 \%)$ & $3(2.8 \%)$ & $10(3.9 \%)$ & $13(3.4 \%)$ & \\
Coughing & $3(2.9 \%)$ & $8(3.1 \%)$ & $11(2.9 \%)$ & $3(2.1 \%)$ & $5(2.0 \%)$ & $8(2.1 \%)$ & \\
Local swelling & $2(1.9 \%)$ & $5(2.0 \%)$ & $7(1.8 \%)$ & $3(2.1 \%)$ & $3(1.2 \%)$ & $6(1.6 \%)$ & \\
\hline Total & $18(14.1 \%)$ & $31(12.1 \%)$ & $49(12.8 \%)$ & $15(10.7 \%)$ & $32(13.1 \%)$ & $47(12.2 \%)$ \\
\hline
\end{tabular}

Table 2a: Organs Condemnation Rates of Sheeps.

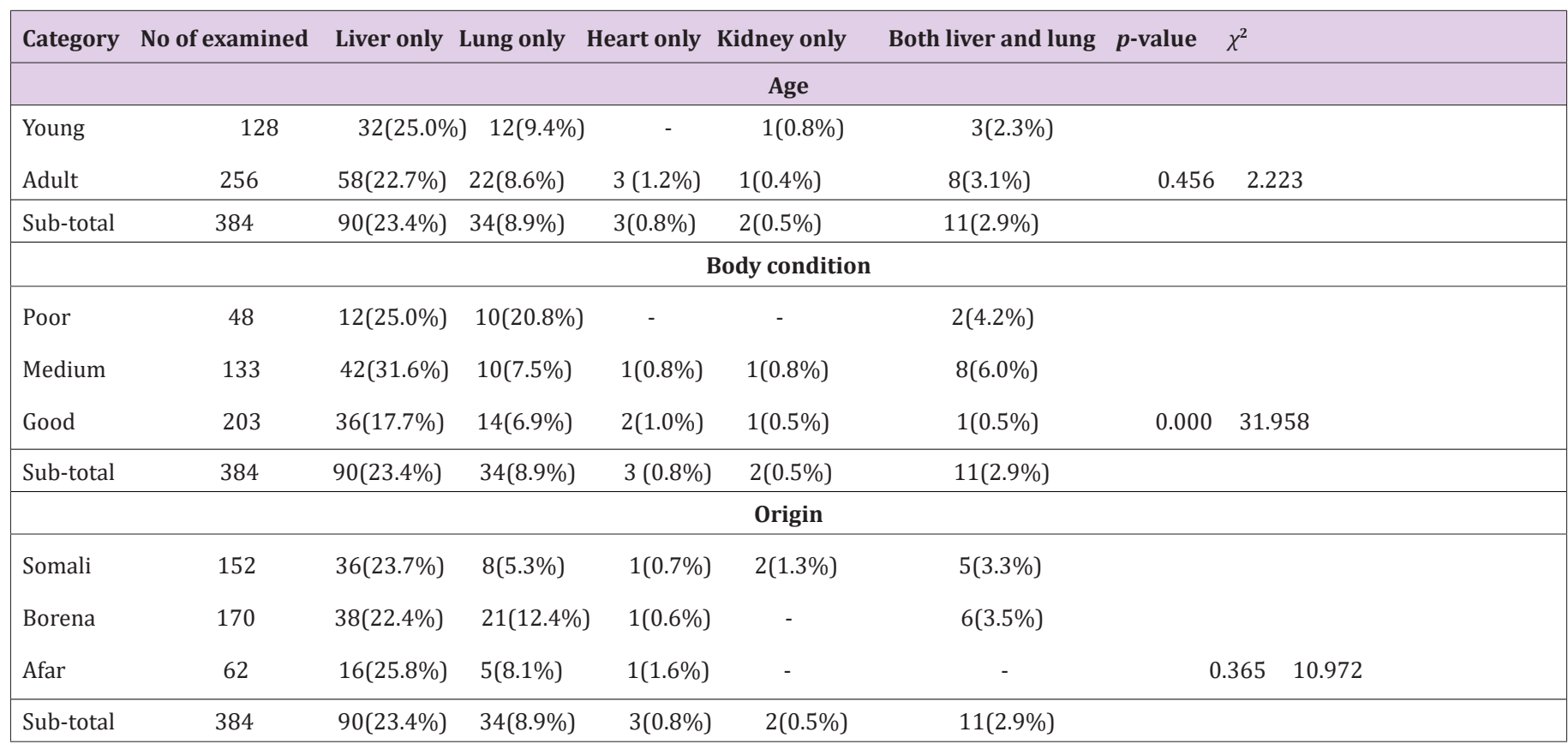

Table 2b: Organs Condemnation Rates of Goats.

\begin{tabular}{|c|c|c|c|c|c|c|c|c|}
\hline Category & No of examined & Liver only Lu & Lung only & Heart only & Kidney only & Both liver and lung & $p$-value & $x^{2}$ \\
\hline \multicolumn{9}{|c|}{ Age } \\
\hline Young & 140 & $35(25.0 \%)$ & $8(5.7 \%)$ & - & - & $4(2.9 \%)$ & & \\
\hline Adult & 244 & $54(22.1 \%$ & $19(7.8 \%)$ & $1(0.4 \%)$ & - & $5(2.0 \%)$ & 0.852 & 1.700 \\
\hline Sub-total & 384 & $89(23.2 \%) \quad 2$ & $27(7.0 \%)$ & $1(0.3 \%)$ & - & $9(2.3 \%)$ & & \\
\hline \multicolumn{9}{|c|}{ Body condition } \\
\hline Poor & 44 & $10(22.7 \%)$ & $7(16.0$ & $\%)$ & - & - & & \\
\hline Medium & 136 & $40(29.4 \%$ & \%) $14(10$. & 3\%) & - & $7(5.1 \%)$ & & \\
\hline Good & 204 & $39(19.1 \%)$ & $6(2.9 \%)$ & $1(0.5 \%)$ & - & $2(1.0 \%)$ & 0.000 & 29.445 \\
\hline
\end{tabular}




\begin{tabular}{|c|c|c|c|c|c|c|c|c|c|}
\hline Sub-total & 384 & $89(23.2 \%)$ & 27 & $.0 \%)$ & $1(0.3 \%)$ & - & \multicolumn{3}{|c|}{$9(2.3 \%)$} \\
\hline \multicolumn{10}{|c|}{ Origin } \\
\hline Somali & 168 & $42(25.0 \%)$ & $9(5$ & $4 \%)$ & $1(0.6 \%)$ & - & $6(3.6 \%)$ & & \\
\hline Borena & 150 & $28(18.7 \%)$ & 11( & $.3 \%)$ & - & - & $3(2.0 \%)$ & & \\
\hline Afar & 66 & \multicolumn{2}{|c|}{$19(28.8 \%)$} & $7(10$ & 6) & & - & 0.310 & 9.347 \\
\hline Sub-total & 384 & $89(23.2 \%)$ & 27 & $7.0 \%)$ & $1(0.3 \%)$ & - & $9(2.3 \%)$ & & \\
\hline
\end{tabular}

During this study period since there was no export market, the organs passed for consumption in the ELFORA Export Abattoir are sold at local market based on their requirement. The rejected organs which found pathologically unfit for human consumption are incinerated in the abattoir to break transmission cycle of the diseases. During the study, 90(23.4\%) and 89(23.2\%) livers of ovine's and caprines, respectively were encountered and rendered the liver to be condemned during the study period are: Stelisia hepatica, Cysticercus tenuicollis, fasciollosis and hydrated cysts (Tables 3-7). Losses from liver condemnation were assumed to occur since hepatic pathology is associated to infection that might have public health importance [30,31] and aesthetic value. Fasciolosis is one of the important parasitic diseases of domestic ruminants, which is caused by digenean trematodes of the genus Fasciola that migrate in the hepatic parenchyma and develop in the bile ducts [32].

Table 3: Parasite Causes of Liver Condemnation.

\begin{tabular}{|c|c|c|c|c|c|c|c|c|}
\hline \multirow[b]{2}{*}{ Category } & \multicolumn{4}{|c|}{ Major parasites } & \multirow[b]{2}{*}{ Stelisia } & \multirow[b]{2}{*}{$p$-value } & \multirow[b]{2}{*}{$\chi^{2}$} & \\
\hline & No of examined & C. tenuicollis & Liver fluke & lated cyst & & & & \\
\hline \multicolumn{9}{|c|}{ Age } \\
\hline Young & 128 & $5(3.9 \%)$ & $8(6.3 \%)$ & $1(0.8 \%)$ & $18(14.1 \%)$ & & & \\
\hline Adult & 256 & $16(6.3 \%)$ & $14(5.5 \%)$ & $3(1.2 \%)$ & $25(9.8 \%)$ & 0.464 & 2.084 & \\
\hline Sub-total & 384 & $21(5.5 \%)$ & $22(5.7 \%)$ & $4(1.0 \%)$ & $43(11.2 \%)$ & & & \\
\hline \multicolumn{9}{|c|}{ Body condition } \\
\hline Poor & 48 & $5(10.4 \%)$ & $3(6.3 \%)$ & $3(6.3 \%)$ & $1(2.1 \%)$ & & & \\
\hline Medium & 133 & $13(9.8 \%)$ & $12(9.0 \%)$ & - & $17(12.8 \%)$ & & & \\
\hline Good & 203 & $3(1.5 \%)$ & $7(3.4 \%)$ & $1(0.5 \%)$ & $25(12.3 \%)$ & 0.060 & 9.190 & \\
\hline Sub-total & 384 & $21(5.5 \%)$ & $22(5.7 \%)$ & $4(1.0 \%)$ & $43(11.2 \%)$ & & & \\
\hline \multicolumn{9}{|c|}{ Origin } \\
\hline Somali & 152 & $9(5.9 \%)$ & $9(5.9 \%)$ & $2(1.3 \%)$ & $16(10.5 \%)$ & & & \\
\hline Borena & 170 & $10(5.9 \%)$ & $10(5.9 \%)$ & $1(0.6 \%)$ & $17(10.0 \%)$ & & & \\
\hline Afar & 62 & $2(3.2 \%)$ & $3(4.8 \%)$ & $1(1.6 \%)$ & $10(16.1 \%)$ & & 0.880 & 1.819 \\
\hline Sub-total & 384 & $21(5.5 \%)$ & $22(5.7 \%)$ & $4(1.0 \%)$ & $43(11.2 \%)$ & & & \\
\hline \multicolumn{9}{|c|}{ Age } \\
\hline Young & 140 & $11(7.9 \%)$ & $6(4.3 \%)$ & - & $18(12.9 \%)$ & & & \\
\hline Adult & 244 & $16(6.6 \%)$ & $9(3.7 \%)$ & $3(1.2 \%)$ & $26(10.7 \%)$ & 0.462 & 0.541 & \\
\hline Sub-total & 384 & $27(7.0 \%)$ & $15(3.9 \%)$ & $3(0.8 \%)$ & $44(11.5 \%)$ & & & \\
\hline \multicolumn{9}{|c|}{ Body condition } \\
\hline Poor & 44 & $4(9.1 \%)$ & $2(4.5 \%)$ & - & $4(9.1 \%)$ & & & \\
\hline Medium & 136 & $13(9.6 \%)$ & $10(7.4 \%)$ & $3(2.2 \%)$ & $14(10.3 \%)$ & & & \\
\hline Good & 204 & $10(5.0 \%)$ & $3(1.5 \%)$ & - & $26(12.7 \%)$ & 0.050 & 5.373 & \\
\hline Sub-total & 384 & $27(7.0 \%)$ & $15(3.9 \%)$ & $3(0.8 \%)$ & $44(11.5 \%)$ & & & \\
\hline & & & & Origin & & & & \\
\hline
\end{tabular}




\begin{tabular}{|lccccc|}
\hline Somali & 168 & $8(4.8 \%)$ & $9(5.4 \%)$ & $2(1.2 \%)$ & $23(13.7 \%)$ \\
Borena & 150 & $10(6.7 \%)$ & $4(2.7 \%)$ & $1(0.7 \%)$ & $13(8.7 \%)$ \\
Afari & 66 & $9(13.6)$ & $2(3.0 \%)$ & - & $8(12.1 \%)$ \\
\hline Sub total & 384 & $27(7.0 \%)$ & $15(3.9 \%)$ & $\mathbf{3 ( 0 . 8 \% )}$ & $44(11.5 \%)$ \\
\hline
\end{tabular}

Table 4: Parasite Causes of Lung Condemnation.

\begin{tabular}{|c|c|c|c|c|c|c|c|}
\hline \multicolumn{8}{|c|}{ Major parasites } \\
\hline Category & No of examined & Lung worm & Hydated cyst & $p$-value & $\chi^{2}$ & & \\
\hline \multicolumn{8}{|c|}{ Age } \\
\hline Young & 128 & $10(7.8 \%)$ & \multicolumn{2}{|c|}{$2(1.6 \%)$} & & \multirow{2}{*}{\multicolumn{2}{|c|}{0.065}} \\
\hline Adult & 256 & $16(6.3 \%)$ & \multicolumn{2}{|c|}{$6(2.3 \%)$} & 0.799 & & \\
\hline Sub-total & 384 & $26(6.8 \%)$ & \multicolumn{2}{|c|}{$8(2.1 \%)$} & & & \\
\hline \multicolumn{8}{|c|}{ Body condition } \\
\hline Poor & 48 & $6(12.5 \%)$ & $4(8.3 \%)$ & & & & \\
\hline Medium & 133 & $10(7.5 \%)$ & - & & & & \\
\hline Good & 203 & $10(4.9 \%)$ & $4(2.0 \%)$ & 0.013 & 9.7 & & \\
\hline Sub-total & 384 & $26(6.8 \%)$ & $8(2.1 \%)$ & & & & \\
\hline \multicolumn{8}{|c|}{ Origin } \\
\hline Somali & 152 & $7(4.6 \%)$ & $1(0.7 \%)$ & & & & \\
\hline Borena & 170 & $17(10.0 \%)$ & $4(2.4 \%)$ & & & & \\
\hline Afar & 62 & $2(3.2 \%)$ & $3(4.8 \%)$ & 0.080 & & & \\
\hline Sub-total & 384 & $26(6.8 \%)$ & $8(2.1 \%)$ & & & & \\
\hline \multicolumn{8}{|c|}{ Caprine } \\
\hline \multicolumn{8}{|l|}{ Age } \\
\hline Young & 140 & $7(5.0 \%)$ & $1(0.7 \%)$ & & & & \\
\hline Adult & 244 & $11(4.5 \%)$ & $8(3.3 \%)$ & & & 0.445 & 0.585 \\
\hline Sub-total & 384 & $18(4.7 \%$ & $9(2.3 \%)$ & & & & \\
\hline \multicolumn{8}{|c|}{ Body condition } \\
\hline Poor & 44 & $4(9.0 \%)$ & $3(6.8$ & & & & \\
\hline Medium & 136 & $10(7.4 \%)$ & $4(2.9 \%)$ & & & & \\
\hline Good & 204 & $4(2.0 \%)$ & & & 0.000 & 12.741 & \\
\hline Sub-total & 384 & $18(4.7 \%)$ & $9(2.3 \%)$ & & & & \\
\hline \multicolumn{8}{|c|}{ Origin } \\
\hline Somali & 168 & $6(3.6 \%)$ & $3(1.8 \%)$ & & & & \\
\hline Borena & 150 & $8(5.3 \%)$ & & $\%)$ & & & \\
\hline Afar & 66 & $4(6.0 \%)$ & $3(4.5 \%)$ & & & 0.396 & 2.031 \\
\hline Sub-total & 384 & $18(4.7 \%)$ & $9(2.3 \%)$ & & & & \\
\hline
\end{tabular}


Table 5: Parasite Causes of Heart Condemnation.

\begin{tabular}{|c|c|c|c|c|c|}
\hline \multicolumn{6}{|c|}{ Major parasites } \\
\hline Category & No of examined & C. ovis & $p$-value & $\chi^{2}$ & \\
\hline \multicolumn{6}{|c|}{ Age } \\
\hline Young & 128 & - & & & \\
\hline Adult & 256 & $3(1.2 \%)$ & 0.219 & 1.512 & \\
\hline Sub-total & 384 & $3(0.8 \%$ & & & \\
\hline \multicolumn{6}{|c|}{ Body condition } \\
\hline Poor & 48 & - & & & \\
\hline Medium & 133 & $1(0.8 \%)$ & & & \\
\hline Good & 203 & $2(1.0 \%)$ & & 1.000 & 0.488 \\
\hline Sub-total & 384 & $3(0.8 \%)$ & & & \\
\hline \multicolumn{6}{|c|}{ Origin } \\
\hline Somali & 152 & $1(0.7 \%)$ & & & \\
\hline Borena & 170 & $1(0.6 \%)$ & & & \\
\hline Afar & 62 & $1(1.6 \%)$ & 1.000 & 0.665 & \\
\hline Sub-total & 384 & $3(0.8 \%)$ & & & \\
\hline \multicolumn{6}{|c|}{ Caprine } \\
\hline \multicolumn{6}{|c|}{ Age } \\
\hline Young & 140 & - & & & \\
\hline Adult & 244 & $1(0.4 \%)$ & & 0.448 & 0.575 \\
\hline Sub-total & 384 & $1(0.3 \%)$ & & & \\
\hline \multicolumn{6}{|c|}{ Body condition } \\
\hline Poor & 44 & & & & \\
\hline Medium & 136 & & & & \\
\hline Good & 204 & $1(0.5 \%)$ & 1.000 & 0.885 & \\
\hline Sub-total & 384 & $1(0.3 \%)$ & & & \\
\hline \multicolumn{6}{|c|}{ Origin } \\
\hline Somali & 168 & $1(0$. & & & \\
\hline Borena & 150 & - & & & \\
\hline Afar & 66 & - & 1.000 & 1.289 & \\
\hline Sub-total & 384 & $1(0.3 \%)$ & & & \\
\hline
\end{tabular}

Table 6: Parasitic Cause of Kidney Condemnation.

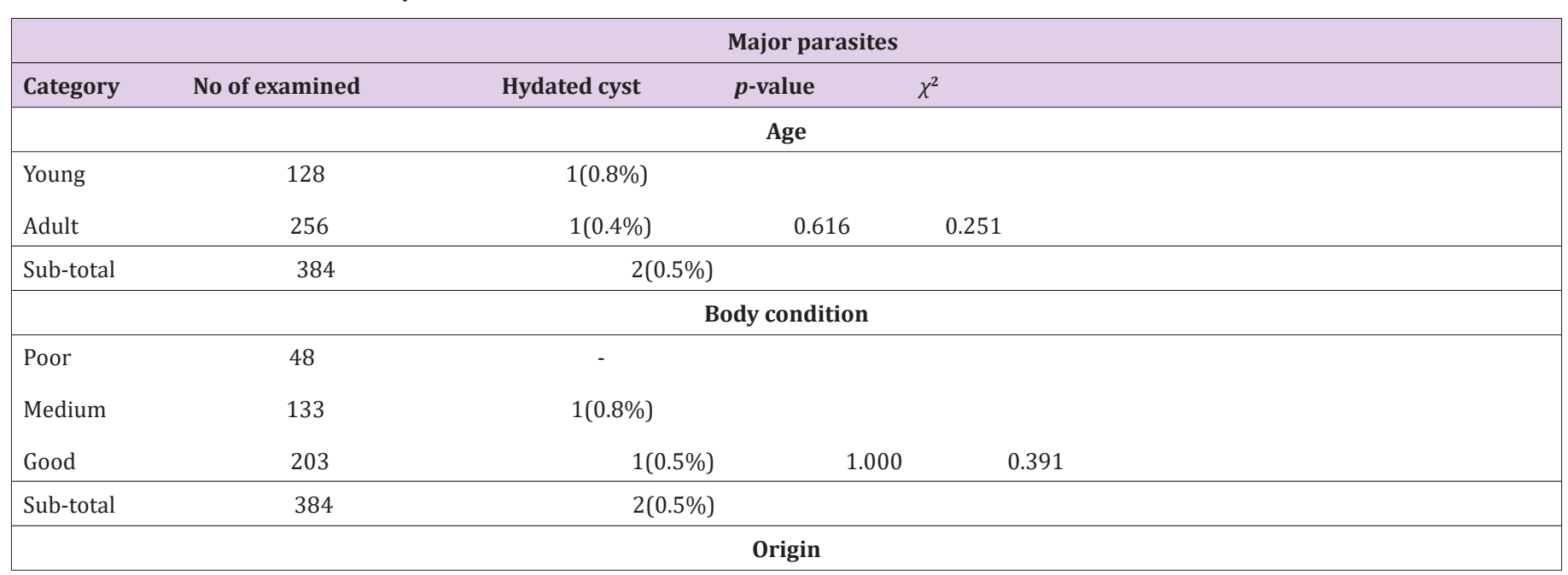




\begin{tabular}{|c|c|c|c|c|}
\hline Somali & 152 & & & \\
\hline Borena & 170 & & & \\
\hline Afar & 62 & - & 0.15 & 3.069 \\
\hline Sub-total & 384 & & & \\
\hline
\end{tabular}

Table 7: Parasitic Cause of Both Liver and Lung Condemnation.

\begin{tabular}{|c|c|c|c|c|c|}
\hline \multicolumn{6}{|c|}{ Major parasites } \\
\hline Category & No of examined & Hydated cyst & $p$-value & & \\
\hline \multicolumn{6}{|c|}{ Age } \\
\hline Young & 128 & $3(2.3 \%)$ & & & \\
\hline Adult & 256 & $8(3.1 \%)$ & 0.665 & 0.187 & \\
\hline Sub-total & 384 & $11(2.9 \%)$ & & & \\
\hline \multicolumn{6}{|c|}{ Body condition } \\
\hline Poor & 48 & $2(4.2 \%)$ & & & \\
\hline Medium & 133 & $8(6.0 \%)$ & & & \\
\hline Good & 203 & $1(0.5 \%)$ & 0.013 & 9.141 & \\
\hline Sub-total & 384 & $11(2.9 \%)$ & & & \\
\hline \multicolumn{6}{|c|}{ Origin } \\
\hline Somali & 152 & $5(\%)$ & & & \\
\hline Borena & 170 & $6(3.5 \%)$ & & & \\
\hline Afar & 62 & - & 0.424 & 2.197 & \\
\hline Sub-total & 384 & $11(2.9 \%)$ & & & \\
\hline \multicolumn{6}{|c|}{ Age } \\
\hline Young & 140 & $4(2.9 \%)$ & & & \\
\hline Adult & 244 & $5(2.0 \%)$ & 0.614 & 0.254 & \\
\hline Sub-total & 384 & $9(2.3 \%)$ & & & \\
\hline \multicolumn{6}{|c|}{ Body condition } \\
\hline Poor & 44 & - & & & \\
\hline Medium & 136 & $7(5.1 \%)$ & & & \\
\hline Good & 204 & $2(1.0 \%)$ & & 0.018 & 7.382 \\
\hline Sub-total & 384 & $9(2.3 \%)$ & & & \\
\hline \multicolumn{6}{|l|}{ Origin } \\
\hline Somali & 168 & $6(3.6 \%)$ & & & \\
\hline Borena & 150 & $3(2.0 \%)$ & & & \\
\hline Afar & 66 & - & 2.768 & & \\
\hline Sub-total & 384 & $9(2.3 \%)$ & & & \\
\hline
\end{tabular}

The prevalence of Fasciolosis by species was slightly higher in sheeps (5.7\%) has compared to goats (3.9\%). However, this difference was not found statistically significant. The result in this study is slightly higher than $3.6 \%$ in Bishoftu HELMEX [15] in sheeps but lower than that reported by other workers. Research conducted by several investigators on ovine fasciolosis prevalence's in different parts of the country revealed, $51 \%$ in Bishoftu by [33], 51\% in Kombolcha by [34], 40.6\% in Gondar [35], 53.3\% in eastern Gojam [36] and 30\% in Ziway [37] and caprine fasciollosis prevalence's revealed 8.3\% in Bishoftu HELMEX [38] which was higher than this report (3.9\%). In General, this study reveals a relatively low prevalence rate than the previous works. This may be due to the increasing awareness of peoples for the disease, decreasment of swampy area due to environmental change and it may also be due to the improvement of veterinary service.

The higher rate of Fasciolosis observed in sheep in comparison with goat could be due to their feeding behavior where sheep are 
usually grazers and goat tend to be more of browsers making them less exposed to parasites. The prevalence of Fasciolosis by age was slightly higher in young (5.2\%) has compared to adults (4.6\%) this may due to the fact that adult animal have repeatedly exposed to fluke infection than young's and develops resistance. The prevalence of Fasciolosis by body condition score was higher in moderate $(8.2 \%)$ than poor $(5.4 \%)$ and good body condition $(2.5 \%)$, this was due to the fact that most of the animals slaughtered in abattoir has moderate body condition next to good body condition but, animals with good body condition have ability to resist diseases. Related to origin, the prevalence was high on animal brought from Somali area (5.6\%) than Borena (4.4\%) and Afar (3.9\%). However, the prevalence rate, epidemiology and the species involvement vary with locality and this is mainly attributed to the variation in the climate and ecological condition such as altitude, rainfall and temperature and livestock management system.

One of the most important factors that influence the occurrence of Fasciolosis in an area is availability of suitable snail habitat. Cysticercus tenuicollis is the cystic stage of Taenia hydatigena, which is found in the small intestines of dogs and cats. Cysts of $C$. tenuicollis are responsible for a high degree of morbidity and mortality in livestock [39]. The prevalence of $C$. tenuicollis by species was higher in goats $(7.0 \%)$ has compared to sheep (5.5\%). However, this difference was not found statistically significant. Similar finding was reported by (Sisay et al., 2007) who have reported prevalence of $38 \%, 30 \%, 32 \%$ and $35 \%$ in goats and $17 \%, 14 \%, 12 \%$ and $15 \%$ in sheep from Haramaya, Harar, Dire Dawa and Jijiga abattoirs; respectively. According to [40]; under condition of high infestation of $C$. tenuicollis most sheep develop protective immunity early in life and this immunity regulate the parasite population, whereas goat develops the immunity more slowly. This considerable degree of immunity against $C$. tenuicollis infection in sheep may be the reason for low prevalence of the parasite in comparison to goats.

The result in this study is higher than 5\% in Bishoftu HELMEX [41] and 4.33\% in Addis Ababa Abattoir Enterprise [42] in sheep but lower than that reported by other workers. C. tenuicollis prevalence in sheep at different part of the country revealed $25.8 \%$ in wolyta [43], 26.4\% in Dire Dawa municipal abattoir [44] and $32.7 \%$ in three export abattoir (ELFORA, Hashim and Luna) by [37]. According to the present study, the overall $C$. tenuicollis prevalence was slightly higher in adults (6.4\%) than in young (6.0\%) sheep and goats. This was agreed with findings of Adem [45] who reported a prevalence of $47.2 \%$ and $37.8 \%$ in adult goats and sheep, and $33.3 \%$ and $33.7 \%$ in young sheep and goats, respectively. Similar finding was reported at HELMEX by [46] who recorded the prevalence of $51.8 \%$ in adult goats and $47.4 \%$ in adult sheep, and 41.4 and $35.8 \%$ in young goats and sheep; respectively.

This may be due to cestode parasites produce significant quantities of antigens in adults than in young, these further protect adult small ruminants from infection [47]. Furthermore, this difference in infection rates between young and adult may be due to the fact that the adult animals (sheep and goats) lived longer and picked larger number of eggs during grazing as compared to the young ones which only lived for a shorter period of time in a given environment and mostly kept indoors. Caprine $C$. tenuicollis prevalence in this study was $7.0 \%$ which was lower than $8.4 \%$ that reported in HELMEX by [41] but slightly higher than $5.31 \%$ at Addis Ababa Abattoir Enterprise reported by [42]. The prevalence of $C$. tenuicollis by body condition score was higher in poor $(9.8 \%)$ than moderate $(9.7 \%)$ and good body condition (3.2\%), this report was confirmed with the findings of [44] who reported that body conditions of sheep was the only risk factor in which the prevalence of $C$. tenuicollis in poor body condition (39.8\%) were found most infected compared to medium (21.8\%) and good (14.5\%) body condition.

The prevalence of $C$. tenuicollis was high on animal brought from Afar area (8.6\%) than Borena (6.3\%) and Somali (5.3\%). This variation in prevalence of $C$. tenuicollis recorded in the study could be due to the variation in environmental condition, the degree of pasture contamination, the difference in culture of handling dog among different societies and the way of rising and grazing of these animals, which are may favors the transmission cycle between ruminants and dogs. Stelisia hepatica is a helminth parasite that has sheep, goats and other livestock as final hosts. The predilection sites of adult Stelisia hepatica are the bile ducts and sometimes the small intestine. Mungube [48] have reported prevalence of liver condemnation due to Stilesia hepatica were $28 \%$ and $22 \%$ in sheep and goats respectively, which is higher than the result obtained in this study (11.2\% and $11.5 \%$ in sheep and goats, respectively) this present study was in agreement with the prevalence reported by [49] who reported prevalence of $31.04 \%$ and $27.02 \%$ in sheep and goats respectively and $35.5 \%$ in sheep and $29 \%$ in goat reported at ELFORA by [50], also Ejeta [51] reported slightly lower prevalence rate of liver condemnation due to Stelisia hepatica at $9.5 \%$ in sheep and higher incidence rate $12.1 \%$ in goats.

The prevalence of Stelisia hepatica in this study was higher both in sheep and goat than $4.33 \%$ in sheep and 3.98\% in goat at Addis Ababa Abattoir Enterprise that recently reported by [42]. This higher prevalence may relate with pasture contamination and occurrence of intermediate host that facilitate their transmission. The epidemiology of Stelisia hepatica was not well established in sheep and goats; hence, it may be difficult to explain why significantly more livers were condemned in goats than in sheep. Its prevalence was higher in good body condition (12.5\%), then moderate $(11.5 \%)$ and poor $(5.2 \%)$ body condition because Stelisia hepatica doesn't have great effect on body condition of the animals. The prevalence of hydated cyst found in this study was $6.5 \%$ and $5.5 \%$ in sheep and goats respectively. The prevalence rate recorded in this study is less than that reported by other investigator in other abattoir of the country.

The recent study by [52] at Hashim export abattoir reported that prevalence in sheep and goats were $16 \%$ and $6.9 \%$, respectively, $17.2 \%$ in sheep and $15.9 \%$ in goat at Addis Ababa abattoir by [53] 
and $29.7 \%$ in sheep and $24.7 \%$ in goat at Jimma by [54] were also have higher prevalence than the current report. The occurrence of such a low prevalence in the current site might have been happened due to reduced backyard slaughter practice, decrease in the population of stray dogs and the presence of control program, as a result of greater awareness created about Echinococcosis among farmers, The prevalence of other workers were $5.3 \%$ ovine and 4.4\% caprine in HELMEX [41] which was lower than this study this might be due to the less abundance and less contact between the infected intermediate and final hosts in study animal origin, 8.7\% ovine and $4.6 \%$ caprine in Gondar [55] which was higher than this study in sheep and lower in goats, $40.6 \%$ ovine and $70 \%$ caprine in Addis Ababa abattoir [56] which was higher than this study.

According to this study the prevalence of hydated cyst was slightly higher in sheep than goat which was 6.5\% and 5.5\%, respectively. This report was in agreement with $7.7 \%$ in sheep and $6.1 \%$ in goat report at Luna export abattoir by [57]. The available literature mentioned in this manuscript or elsewhere showed that the prevalence of hydatidosis is high in sheep compared to goats. This may be due to the difference in feeding habits that goats are browsers. The prevalence of hydatidosis was slightly higher in small ruminant having poor (13\%) followed by medium body condition (8.6\%) and good (2.7\%). (Polydrous, 1981) explained that in moderate to severe infections, the parasite may cause retarded performance and growth, reduced quality of meat and milk, as well as live weight loss. According to this study high prevalence was recorded on adult animals (6.8\%) than young (4.5\%). Prevalence rate increases as the age of animal increases [58]. Therefore, the highest prevalence rate is expected in older animals.

The general trend of age prevalence data was the infection rate increases with age, for the two animal species as a result statistical significance was observed $(\mathrm{P}<0.05)$ between the young and adult of both species. Prevalence related with origin includes $6.6 \%$ in Somali, 5.6\% in Borena and 5.5\% in Afar. The lower prevalence found in both species in this study may be ascribed to the origin of the slaughtered animals which was from low land areas where the environmental condition such as high temperature and low humidity exists. In this study, it has been shown that hydatid cysts occurred most commonly in the lung 17 (2.2\%) followed by liver 7 $(0.9 \%)$. This agrees with the findings of [59] and [60], which show that the lung and liver are the most common sites of hydatid cyst in domestic animals. This might be due to the fact that animals are mainly slaughtered at older age, during which period the liver capillaries are dilated and most oncospheres pass directly to the lungs; additionally, it is possible for the hexacanth embryo to enter the lymphatic circulation and be carried via the thoracic duct to the heart and lungs in such a way that the lung may be infected before or instead of liver Jobre (1996).

The prevalence of Cysticercus ovis recorded in this study $(0.8 \%$ and $0.3 \%$ in sheep and goat respectively) which was slightly higher than $0.65 \%$ in sheep and lower than $1.3 \%$ in goat that reported at HELMEX by [41]. Other than this there is no enough documented report on this parasite. Therefore, they could not discuss the result of the finding in comparison to other workers in the country due to lack documented information in the subject. The prevalence of lung worm found in this study was $6.8 \%$ and $4.7 \%$ in sheep and goats respectively, which was lower as compared to recently reported $10.9 \%$ and $8.8 \%$ in sheep and goats respectively at HELMEX by [41]. The other reports in goats were made in other abattoir $7.5 \%$ in Bishoftu Hashim abattoir by Eschew (2007), which was higher than this study report and over all prevalence rate $26.7 \%$ at Jimma [61]. The lower prevalence in this study may be due to origin of examined animals and the reduction of close association between intermediate host and final host.

The prevalence of lung worm by species was slightly higher in sheep (6.8\%) as compared to goats $(4.7 \%)$. This may be due to the fact that sheep predominantly graze; pick up more parasites but goats with their browsing behavior consume uncontaminated matter with parasite larvae, so being less exposed to infective larvae. The prevalence by age revealed that higher infection rates was recorded in animals with young age $(6.3 \%)$ than that recorded in animals with adult age (5.4\%) and these was no statistically significant differences was observed $(\mathrm{P}>0.05)$ between age group of both species and this parasite. This might be since all animals are kept under the same management system, extensive type in which all animals of different ages have equal chance of being infected. Radostitis [31] and Mekonnen [62] reported that young sheep and goats were found to be infected more than adults, and this might be associated with the naturally acquired immunity against infection in older animals which slowly developed due to the previous exposure and better immunity against re-infection after recovering from the disease.

Body condition scores were also found to be a risk factor ( $\mathrm{P}$ $<0.05$ ) in the prevalence of lung worm infection. The prevalence according to body condition grade was $10.9 \%, 7.4 \%$, and $3.4 \%$ in poor, medium and good body condition scores of sheep and goats, respectively. This might be due to poorly nourished animal appear to be less competent in getting rid of infection although it is unusual for well-fed animals to succumb to the disease provided the right environmental conditions are available Evidently, the infection with a parasite by itself might results in progressive emaciation of the animals [31]. The prevalence of lungworm in this study was higher in shoats brought from Borena (7.8\%) than Afar (4.7\%) and Somali (4.1\%), these differences in the prevalence of lungworms of small ruminants might be associated with difference in nutritional status, level of immunity, management practice of the animal, rain fall, humidity, temperature and altitude differences [63-65].

The economic losses incurred during this study as a result of condemnation or rejection of edible organs of sheep and goat was estimated to be about 45, 379.00 ETB per annum in Bishoftu 
ELFORA export abattoir from domestic market. This was lower than the report of [41] at HELMEX export abattoir which was $47,272.5$ USD. The indirect losses from body weight gain, mortality at the farms, public health implications were not included in the analysis in this study.

\section{Conclusion and Recommendations}

In conclusion, parasitic diseases was the major causes of financial loss through organ condemnation at Bishoftu ELFORA export abattoir, which may also reflect the same scenario in other slaughter houses in Ethiopia. According to this study, the most frequently condemned organs were livers and lungs. Stelisia hepatica followed by liver fluke in the liver, and lungworm followed by hydated cyst in the lung were the major parasites that cause those condemnations. The overall prevalence of major parasitic cause of organ condemnation in this study was found to be $34.6 \%$ and this result in extensive financial wastes about 45,379.00 ETB. Improper managemental practices of animals on farm or at home and improper disposal or handing of offal's in control of parasitic diseases result in severe economic losses and consequently exclude the country from attractive international market there by greatly redacting the country; foreign exchange earnings. In line with finding of this study the following recommendations are forwarded so as to resolve and reduces the significant economic loss incurred.

a) Public health education to avoid eating of raw meat, canine health care, stray dog management and proper disposal of condemned organs and small ruminant management system should be required.

b) Regular deworming of small ruminants with effective antihelminthes and grazing management of animals during dry season to avoid access of the animals to the parasite's eggs should be practiced in the areas.

c) Education of farmers, urban dwellers, abattoir workers, butchers and dog owners on proper disposal of offals.

d) Awareness creation to animal owners regarding the route of infection and economic importance of the disease so that, they can actively participate in the control of the disease.

e) Expanding Veterinary service provider in the area with the facility to diagnose and treat parasite infected animals to mitigate production losses should be crucial.

f) Further studies should be carried out in small ruminants brought from differentareas and that are going to be slaughtered in different abattoirs of the country and introduce preventive measures to reduce unnecessary financial losses encountered in the industry.

\section{References}

1. Duguma B, Tegegne A (2012) Smallholder livestock production system in Dandi district, Oromia Regional State, Central Ethiopia. Global Vet 8(5): 472-479.
2. MacDonald M, Simon J (2011) Climate, food security and growth Ethiopia's complex relationship with livestock.

3. Alemu Y, Merkel R (2008) Sheep and Goat Production Handbook for Ethiopia: Ethiopia Sheep and Goat Productivity Improvement Program / ESGPIP/, Ministry of Agriculture and Rural Development: 15-53.

4. (2016) Central Statistical Agency (CSA) Federal Democratic Republic of Ethiopia Central Statistical Agency Agricultural Sample Survey 2015/16. II. Report on livestock and livestock characteristics. Stat Bulletin 2: 532.

5. (2009) FAO STAT, Livestock production primary Food and Agricultural Organization of the United Nations. Retrieved December 2009.

6. Nurit M, Zerihun H, Serkalem M (2012) Major Cause of Liver Condemnation and Associated Financial Loss at Kombolcha Elfora Abattoir, South Wollo, Ethiopia. European J Appl Sci 4(4): 140-145.

7. Jibat T, Ejeta G, Asefaw Y, Nusie A (2006) Causes of abattoir organ condemnation in apparently healthy slaughtered sheep and goats at HELMEX Abattoir, Debre Zeit, Ethiopia. Revue de médecine vétérinaire 159(5): 305-311.

8. Alemayehu R, Nebyou M, Bekele M, Desta B, Dessie Sh, et al. (2009) Major causes of organs and carcass condemnation in small ruminants slaughtered at Luna Export Abattoir, Oromia Regional State, Ethiopia. Prev Vet Med 110(2): 139-148.

9. Ezana G (2008) Major diseases of export-oriented livestock in export abattoirs in around Adalben woreda, Debre Zeit. DVM thesis (Veterinary Medicine): 32

10. Abebe F, Yilma J (2012) Estimated annual economic loss from organ condemnation, decreased carcass weight and milk yield due to bovine hydatidosis (Echinococcus granulosus, Batsch, 1786) in Ethiopia. Ethiop Vet J 16(2): 54.

11. Aynalem M, Kassaye A, Birhanu H, Gezahegn A, Gemechu C (2015) Major Cause of Organ and Carcass Condemnation and Its Financial Loss at Bishoftu Elfora Export Abattoir. Inter J Nut Fd Sci 4(3): 364-372.

12. Alton G, Lpeah D, Bateman K, Mc Nab W, Berk O (2010) Factors associated with whole condemnation rates in provincially inspected abattoir in Ontario 2001-2007. Implication for food animal syndromic surveillance. BMC Vet Res 6: 42.

13. Hassan B, Mohammad A, Mehra K (2012) A retrospective study of abattoir condemnation due to parasitic infections: economic importance in Ahwaz, southwestern Iran. J Parasitol 98(5): 954-957.

14. Abebe G (1995) Current status of veterinary education and health research in Ethiopia. In: Veterinary Medicine Impact on Animal Health and Nutrition in Africa Proceeding of an International Conference: 133138.

15. Jibat $\mathrm{T}$ (2006) Causes of organ and carcass condemnation in small ruminant slaughtered at Debre Zeit HELMEX abattoir. DVM thesis, FVM, AAU, Debre Zeit, Ethiopia.

16. Yifat D, Gedefaw D, Desie S (2011) Major causes of organ condemnation and financial significance of cattle slaughtered at Gondar Elfora Abattoir, Northern Ethiopia. Glob Vet 7: 487-490.

17. Nebyou M (2014) Major Causes of organs and carcass condemnation in cattle slaughtered at Nekemte Municipality Abattoir, East Wollega, Ethiopia. Glob Vet 13: 278-284.

18. (2003) National meteorology service agency (NMSA) National meteorology service agency. Addis Ababa, Ethiopia.

19. Abebe G (2007) Body condition score of sheep and goats, Ethiopian sheep and goat's production improvement program (ESGPIP): 3.

20. Steel M (1996) Goats: The tropical agriculturalist. London and Basing Stoke Macmillan Education Ltd. ACCT: 79-83.

21. Thrusfield M (2005) Veterinary epidemiology ( $3^{\text {rd }}$ edn.). Blackwell Science Ltd, UK, 182- 198. 
22. Nicholson M, Butterworth M (1986) A guide to condition scoring of zebu cattle. ILCA, Addis Ababa Ethiopia: 212-235.

23. Gracy J Collins D, Huey R (1999) Meat hygiene, ( $3^{\text {rd }}$ edn.). WB Saunders Company Ltd, 669-678.

24. (1994) FAO. Manual of meat inspection for developing countries. Anim Prod Hlth: 119-359.

25. Getaw A, Beyene D, Ayana D, Megersa B, Abunna F (2010) Hydatidosis: prevalence and its economic importance in ruminant slaughtered at Adama municipal abattoir, CentralOromia, Ethiopia. Acta Trop 113(3): 221-225.

26. Getachew E (2008) Major diseases of export-oriented livestock in export Abattoirs in/around Ada Liben Wereda, DedbreZeit, Faculty of Veterinary Medicine and Haramaya University, Ethiopia, DVM Thesis.

27. Orgurinade A, Orgurinade B (1980) Economic importance of bovine fasciolosis in Nigeria. Trop Anim Heal Prod 12(3): 155-160.

28. Alembrhan A, Haylegebriel T (2013) Major Causes of Organ Condemnation and Economic Loss in Cattle Slaughtered at Adigrat Municipal Abattoir, Northern Ethiopia. Vet World 6(10): 734-738.

29. Cadmus S, Adesokan H (2009) Causes and implication of bovine organs/ offal condemnations in abattoirs in western Nigeria. Trop Anim Hlth Prod 41(7): 1455-1463.

30. Budke C, Campos P, Qian W, Torgerson P (2005) A canine purgation study and risk factor analysis for echinococcosis in a high endemic region of the Tibetan plateau. Vet Parasitol 127(1): 43-49.

31. Radostitis O, Gay C, Chliff K, Constable P (2007) A textbook of diseases of cattle, horses, sheep, pigs and goats (10 $0^{\text {th }}$ Edn.) St. Louis Philadelphia, London, pp. 1568- 1569.

32. Bowman D (2003) Georgis Parasitology for veterinarians. ( $8^{\text {th }}$ edn.). Saunders, USA, 124-240.

33. Michael A (2004) Infection prevalence of ovine fasciolosis in irrigation schemes along the upper Awash River basin and effects of strategic anthelminthic treatment in selected up stream areas. MS Thesis, Addis Ababa University, School of graduate studies, Ethiopia, p. 79.

34. Ahmed M (2009) Prevalence of ovine Fasciolosis in and around Kombolcha. DVM Thesis, Universtiy of Gondar, Gondar, Ethiopia.

35. Yimam M (2003) Major cause of organ condemnation in ruminants slaughtered at Gondar Abattoir, North Western Ethiopia, Debre Zeit: FVM. AAU, DVM Thesis, p. 1-9.

36. Beyazen C (1995) Preliminary study on epidemiology of fasciollosis in Eastern Gojam region, Ethiopia. DVM thesis, FVM, AAU, Debre Zeit.

37. Abdela A (2006) Methacestode of small ruminants of three export abattoirs (ELFORA, HELMEX and Luna), MSc thesis, FVM, AAU, p. 33-45.

38. Seblewengel A (2007) Causes of organ condemnation in HELMEX Abattoir. Proceeding of the $4^{\text {th }}$ national livestock improvement conference. Institute of Agricultural research, Addis Ababa, Ethiopia.

39. Yehualashet B, Aklilu Z, Tsegaye A (2012) Prevalence and economic importance of liver parasites: Hydatid cyst, Fasciola species and cysticercus tenuicollis in sheep and goats slaughtered at Addis Ababa abattoir enterprise in Ethiopia. J vet med anim health 5: 1-7.

40. Torgerson P, Williams D, Abo Shehada M (1998) Modelling the prevalence of Echinococcus and Taenia species in small ruminants of different ages in northern Jordan. Vet Parasitol 79(1): 35-51.

41. Mohammed H, Said H, Gebeyow C, Mukarim A (2017) Parasitic Cause of Organ and Carcass Condemnation in Small Ruminant Slaughtered at Helmex Abattoir, Debrezeit, Ethiopia. Inter J Res Stud Bioscie 5(4): 2230 .

42. Assefa D, Gezaheng E, Abera B, Eticha E, Lemma B, et al. (2017) Major Cause of Organ and Carcass Condemnation in Apparently Healthy Small
Ruminant Slaughtered at Addis Ababa Abattoir Enterprise, Ethiop. J Vet Sci Technol 8: 419.

43. Muktar R (1988) Preliminary survey of gastro- intestinal helminthes in dogs, cysticercus tenicullolis in sheep and goats, Hydatidosis in sheep, goats and cattle, at walayta Awraja. DVM thesis, AAU. FVM, Debre Zeit, Ethiopia.

44. Endale M, Shihun S, Jemere B, Desie S (2013) Sheep and goats Cysticercus tenuicollis prevalence and associated risk factors, Afri. J Agri Res 8(24): 3121-3125.

45. Adem M (2006) Metacestodes of small ruminants: prevalence at three export abattoir (ELFORA, Hashim and Luna), MSc Thesis, FVM, Addis Abeba University, Ethiopia.

46. Woynshet S (2008) Cross sectional study on the prevalence of Cysticercus tenuicollis in visceral organs of sheep and goats slaughtered at HELMEX export abattoirs. DVM Thesis, FVM, and Addis Ababa University, Ethiopia, 8-13.

47. Zahang E, McManus D (2006) Recent advances in the immunology and diagnosis of Echinococcosis. FEMS Immunol Med Microbiol 47(1): 24 41.

48. Mungube E, Bauni S, Tenhagen B, Wamae L, Nginyi J, et al. (2006) The prevalence and economic significance of Fasciola gigantica and Stilesia hepatica in slaughtered animals in the semi-arid coastal Kenya. Trop Anim Hlth Prod 38(6): 475-483.

49. Ashenafi T (2010) Prevalence of Stilesia hepatica,fasciola species and Cysticercus tenuicollis livers of sheep and goats slaughtered at HELMEX abattoir, Debrezeit, DVM Thesis, Faculty of veterinarymedicine, Addis Ababa University, Debrezeit.

50. Muleta L, Mekonnen A (2017) Prevalence and Monetary Loss of Stilesia Hepatica among Small Ruminants Slaughtered at ELFORA Industrial Abattoir. Int J Adv Res Biol Sci 4(10): 4-9.

51. Ejeta G, Molla B, Alemayehu D, Muckle A (2008) Salmonella serotypes isolated from minced beef, mutton and pork in Addis Ababa Ethiopia. Revue Med Vet 155: 547-551.

52. Mebrie Z, Basaznew B, Samuel D, Asmelash T (2015) Hydatidosis Prevalence, Cyst Viability and Organ Distribution and Economic Significance in Small Ruminants Slaughtered at Hashim Nur's Export Abattoir, Debrezeit, Ethiopia. Acta Para Glob 6(3): 154-163.

53. Kebede N, Mitiku A, Tilahun G (2010) Retrospective survey of human hydatidosis in Bahir Dar, north-western Ethiopia. East Mediterr Hlth J 16(9): 937-941.

54. Bersissa K, Ahmedin M (2012) Prevalence, organ distribution, risk factors and financial losses of hydatid cysts in sheep and goats slaughtered in restaurants in Jimma, south western Oromia. Comparative Clis Patho 21(5): 1-9.

55. Tamene M (1987) Preliminary study of Echinococcosis in livestock in Gondar. DVM thesis, AAU, FVM, Debrezeit, Ethiopia.

56. Gemeda B (1988) Preliminary study on Hydatidosis in livestock (cattle, sheep goats and pigs) slaughtered at Addis Ababa abattoir. FVM, Debre Zeit, Ethiopia.

57. Daniel F (2012) Economic importance of Organs Condemnation due to Faciolosis and Hydatidosis in Cattle and Sheep Slaughtered at Dire-Dawa Abattoir. DVM Thesis, FVM, Addis Ababa univ. Debre-Zeit, Ethiopia.

58. (2001) WHO/OIE. WHO/OIE Manual on Echinococcosis in Humans and Animals: a Public Health Problem of Global Concern. Parasitol Trop Anim Hlth and Prod 17: 3-4.

59. Eckert J, Deplazes P (2004) 'Biological, epidemiological, and clinical aspects of echinococcosis, a zoonosis of increasing concern'. Clin Micro Rev 17(1): 107-135.

60. Kebede N, Gebre-Egziabher Z, Tilahun G, Wossene A (2009) Prevalence and Financial Effects of Hydatidosis in Cattle Slaughtered in Birre- 
Sheleko and Dangila Abattoirs, Northwestern Ethiopia, Zoonoses Pub Hlth 58(1): 41-46.

61. Weldesenebet D, Abdu M (2012) Prevalence of Small Ruminant Lung Worm Infection in Jimma Town Dawit Weldesenbet. Glob Vet 8(2): 153159.

62. Mekonnen A, Abebe F, Yohanes E (2011) Study on prevalence of Lungworm infection in small ruminants in Gondar town, Ethiopia. J Vet Adv 10(13): 1683-1687.

ISSN: 2574-1241

DOI: 10.26717/BJSTR.2019.23.003908

Debela Abdeta. Biomed J Sci \& Tech Res

(C) $(1)$ This work is licensed under Creative Commons Attribution 4.0 License

Submission Link: https://biomedres.us/submit-manuscript.php
63. Borji H, Azizzadeh M, Ebrahimi M, Asadpour M (2012) Study on small ruminant lungworms and associated risk factors in northeastern Iran. Asian Pacific J trop med 5(11): 853-856.

64. Polydrous K (1981) Animal health and economics case study: Echinococcosis with the reference to Cyprus. Bull Int Epis 93(5): 195203.

65. Sisay M, Uggla A, Waller P (2007) Prevalence and seasonal incidence of nematode parasites and fluke infestation of sheep and goat in eastern Ethiopia. Trop Anim Hlth Prod 39(7): 521-531.

$\begin{array}{ll}\text { BIOMEDICAL } & \text { Assets of Publishing with us } \\ \text { RESEARCHES } & \text { - Global archiving of articles } \\ & \text { - Immediate, unrestricted online access } \\ & \text { - Rigorous Peer Review Process } \\ & \text { - Anttps://biomedres.us/ }\end{array}$

